\title{
Organizational Influences in Technology Adoption Decisions: A Case Study of Digital Libraries
}

\section{Fatih Oguz}

The purpose of this study was to understand the organizational level decision factors in technology adoption in the context of digital libraries. A qualitative case study approach was used to investigate the adoption of a specific technology, XML-based Web services, in digital libraries. Rogers's diffusion of innovations and Wenger's communities of practice were the theories used to frame the study. The data collected through interviews were triangulated with documentary evidence and a comprehensive member check. Four organizational level influences identified when making technology adoption decisions in the context of digital libraries were organizational structure, management style, focus and direction of the program, and relationships with external entities. Attributes including program size, organizational culture and availability of financial resources contributed to these organizational level influences whereas program size did not appear to have an effect. Informal communication mechanisms were found to inform and influence the decision-making process.

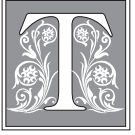

he speed of technological advances in information and communication technologies within the last two decades has enabled libraries to offer digital library services to create, develop, and provide innovative information resources and services. Digital libraries (DLs) bring enhanced and expanded services to libraries, add value to existing user services, and transform the information landscape by improving and changing the means of knowledge access, creation, use, and discovery across disciplines regardless of temporal and geographical barriers. ${ }^{1}$ Lesk defines a DL as a collection of organized information in digital format. ${ }^{2}$

The evolving information landscape presents challenges such as the lack of standards and ineffective information retrieval mechanisms. ${ }^{3}$ Interoperability is one such challenge that needs to be addressed by DLs because it is key to connecting disparate systems and resources. ${ }^{4}$ The size, heterogeneity, and complexity of today's information resources and metadata standards are important variables to consider when building or integrating DLs because they pose immense challenges for interoperability. ${ }^{5} \mathrm{XML}-$ based web services (WS), a next generation of web-based technology for machine-to-

Fatih Oguz is Assistant Professor in the Department of Library and Information Studies at the University of North Carolina at Greensboro; e-mail:f_oguz@uncg.edu. (c) 2016 Fatih Oguz, Attribution-NonCommercial (http://creativecommons.org/licenses/by-nc/3.0/) CC BY-NC. 
machine information exchange, offer an open, standards-based, interoperable, and vendor-neutral platform to integrate disparate applications and systems seamlessly (such as Search/Retrieve via URL [SRU] and Open Archives Initiative [OAI]). ${ }^{6}$

Decision makers in information organizations or services often face the situation where they would need to consider, adopt, or reject an innovation that can be a specific technology, an application, a framework, or an idea related to DLs. Technological innovations are critical for the success and sustainability of organizations that rely increasingly and heavily on the use of information and communication technologies, such as DLs. Such decisions are informed and influenced by a variety of factors at different levels: personal (for example, one's skill set), technology-specific (for instance, scalability), and organizational (such as management style). ${ }^{7}$ Therefore, it is important for DL administrators and managers to better understand how such innovations can be promoted and adopted.

Research on innovation in the context of nonprofit organizations has been limited. ${ }^{8}$ As nonprofit organizations, academic libraries experience unique challenges compared to for-profit ones, in terms of external funding agency requirements, diverse user needs, and ethical issues. ${ }^{9}$ Additionally, a majority of innovation adoption research in DLs has primarily focused on the end users' adoption of DLs or DL services, while only very few studies have focused on technology adoption. ${ }^{10}$ The current research, therefore, aims to fill an important gap by investigating the role of organizational level influences and decision factors in adoption of an emerging technology to enhance services offered by DL programs. A case study approach was used to examine this complex phenomenon to understand the decision-making process and organizational-level influences. ${ }^{11}$ The study also explored organizational characteristics, including management style of the administrators and organizational structure, which contribute to the decision-making processes.

The adoption of WS technologies can be viewed as a revelatory case to the extent that organizational influences (organizational structure, management style, focus and direction, and external relationships) identified in this study may be applicable to similar adoption decisions for key technologies or standards in the context of DLs.

\section{Literature Review}

This study engaged Rogers' diffusion of innovations (DOI) theory to explore the adoption of WS technologies in DL environments. ${ }^{12}$ According to DOI theory, communication channels play a vital role in the diffusion process, and the extent of exposure to formal and informal communication channels increases a potential adopter's chance of knowing about an innovation earlier than others. The study specifically focused on Wenger's communities of practice (CoPs) theory to better understand the roles of informal communication mechanisms (such as interpersonal networks) in technology adoption. ${ }^{13}$

\section{The Theory of Diffusion of Innovations}

Rogers defines an innovation as an idea, behavior, practice, or object perceived as new by the adopter (like an organization or an individual). ${ }^{14}$ Diffusion is understood as "the process in which an innovation is communicated through certain channels over time among the members of a social system."15 Therefore, diffusion of an innovation can be described as a social process that is influenced by factors, such as characteristics of the innovation (such as relative advantage) and the decision-making unit (such as individual characteristics) depending on the level of adoption (individual vs. organizational). Innovations particularly with greater relative advantage, compatibility, triability, observability, and less complexity are more likely to be adopted faster than others lacking these characteristics. ${ }^{16}$ However, structural factors (like formalization and 
centralization) and innovation-specific characteristics (for instance, cost, profitability, and social approval) need to be taken into consideration, especially in organizational settings. ${ }^{17}$

Adopters make voluntary decisions to accept or reject an innovation based on the benefits they expect; however, in organizational settings such decisions may be supported or mandated by management. ${ }^{18}$ Both administrative and lower-level employees can introduce innovations; administrative innovations tend to originate at the higher levels of hierarchy and then move from top to bottom as opposed to technical innovations. ${ }^{19}$ Skilled individuals in the technical area of an organization may have more influence on decisions related to technological innovations when management lacks expertise. ${ }^{20} \mathrm{Zmud}$, however, found managerial influence was stronger for technological innovations. ${ }^{21}$ Furthermore, technological innovations are generally more observable, have higher triability, and are perceived to be more beneficial, simpler, and easier to implement than administrative innovations.

\section{Decision-Making Process}

Most adopters prefer to have a subjective evaluation of an innovation from others whom they tend to share similar personal characteristics including social status and common interests. ${ }^{22}$ Such contacts are perceived to possess more knowledge about the innovation. Face-to-face communication is the typical way of building and sharing tacit knowledge, as it provides a much richer experience for the potential adopter. Tacit knowledge is derived from experience, incorporates beliefs and values, and is more subjective and intuitive. Today's electronic communication technologies (such as Web 2.0 and social media) have made such interactions possible online. ${ }^{23}$

Organizational structure and management style of the administrator often determine how decisions are made. ${ }^{24}$ Although most libraries are structured as bureaucracies, they have been adopting a more organic structure to better respond to the demands of the better-educated workforce, changing user needs, and evolving technologies. ${ }^{25}$ As libraries change, administrators have adopted a more flexible management style allowing input from staff and enabling them both to contribute to solving problems and to the decision-making process. ${ }^{26}$ The level of employee participation represents their familiarity with the decision to be made and influence on the final decision. ${ }^{27}$ This management style is characterized as a participative management style, which empowers employees and contributes to job satisfaction and improvement in organizational effectiveness. ${ }^{28}$

Rogers identified three types of innovation decisions: optional, collective, and authority innovation-decisions. ${ }^{29}$ Optional innovation-decisions are usually made at the personal level and are influenced by personal characteristics of the individual, and norms of the informal social system, of which he or she is a part, and through informal communication channels, including CoPs and other forms of interpersonal communication means. In collective innovation-decisions, decisions are often made through consensus among members of a social system (for example, a DL department or program). Information acquired through informal communication channels commonly plays some role in the decision-making process while building consensus. Authority innovation-decisions are made by relatively few individuals who possess power, status, and/or technical expertise. Compliance and compatibility of decisions with existing organizational (such as academic library or DL) rules, policies, and norms are significant factors affecting the authority innovation-decisions. Collective and authority innovation-decisions are more common than optional innovation-decisions in organizational settings. 


\section{Informal Communication Process}

Formal communication is coordinated based on common rules, policies and regulations, and standard procedures through memos, reports, and other standardized communications. ${ }^{30}$ These formal communication conventions are specified in advance, unidirectional, and relatively impoverished. ${ }^{31}$ On the other hand, informal communication is interactive, spontaneous, and rich in content and supports organizational or group coordination when formal communication mechanisms (such as rules) are not available under conditions of uncertainty. ${ }^{32}$ The nature of the relationship among individuals and their social status affect the formality of the communication. Informal communication channels (such as interpersonal) are the most effective mechanisms for transferring tacit knowledge and accelerate the knowledge searching and transferring process within a group, and organizations are often less explicit when it comes to regulating social relationships than work procedures. ${ }^{33}$ In addition, informal communication channels enable members of a group to be aware of each other's expertise and skills. ${ }^{34}$

Though organizations are relatively less explicit in regulating informal communication, organizational culture is a driving force in informing and shaping employees' informal communication behavior with their peers in and outside the organization. Organizational culture refers to a shared belief system among members of a social system. ${ }^{35}$ Though research on the relationship between organizational culture and innovation is inconclusive, organizational culture informs or may even dictate individuals' communication practices. ${ }^{36}$

\section{Communities of Practice (CoPs)}

CoPs are composed of people who share a concern, common problems, or a passion about the domain and want to gain more knowledge and expertise by interacting regularly. ${ }^{37}$ Three components are crucial in a CoP: domain, practice, and community. Domain addresses the issues related to purpose of a community, such as topics, and benefits pertinent to its members so that a common understanding of the domain can be developed. The practice refers to the work of what its members do as practitioners. ${ }^{38}$ A community is defined as a group of people who engage in joint learning activities, build relationships, and help each other regularly in pursuing their interests in the domain. ${ }^{39}$ Continuity in their interactions allows them to develop a sense of belonging, identity, and commitment. ${ }^{40}$ Commitment to the domain is an important distinguishing characteristic of CoPs from other social structures.

CoPs provide a learning environment through social participation. CoPs make knowledge an integral part of their ongoing activities and interactions. Members can compare, verify, and benchmark their professionally developed expertise in the field against their colleagues' knowledge. CoPs do not only improve the business outcomes for organizations but foster professional development for their members by creating a rich environment for knowledge creation, exchange, and dissemination. ${ }^{41}$

\section{Methodology}

Adoption of a new technological development is a complex social process involving characteristics of the adopter (personal vs. organizational), the innovation, and the social group to which the adopter belongs. The exploratory and descriptive nature of this study afforded the use of a case study approach to allow discovery and description of the social processes involved in decision making. The study employed a case in decision making related to a specific technology in the context of DLs as a method of exploring decision factors at the organizational level.

The following research questions guided the study: 
a. What are the organizational-level influences that contribute to the decisionmaking process in technology adoption?

b. What roles do DL communities of practice play in technology adoption decisions?

Data sources for the study included semistructured interviews with informationrich respondents, documentary evidence, and member-check. Documentary evidence included a wide range of documents from official reports and meeting minutes to publications and presentations authored by respondents.

\section{Research Design}

The use of case study methodology to study a case of technology adoption in the successful development of DLs provided a significant opportunity to explore the roles and influence of informal communication channels on the decision-making process. Studying an innovation that is under consideration and still in its early stages of adoption is crucial in lowering the recall data problem. ${ }^{42}$ This particular technology was introduced in early 2000s and has already been adopted and/or supported by some of the popular DL systems and programs (such as DSpace and California Digital Library).$^{43}$

A case study approach aims at describing a complex social phenomenon "in depth and detail, holistically, and in context." 44 This approach is especially appropriate for studies investigating a complex social phenomenon in the context of organizations "when the boundaries between phenomenon and context are not clearly evident." ${ }^{45}$ The complex social phenomenon studied here is the decision-making process in DLs where a number of activities, entities, processes, motivations, and forces are at play.

Respondents and DL programs for the study were selected based on distinctive characteristics including characteristics summarized in table 1, current status of the decision (examples: adopt, reject), role (for example, designer or manager) of the staff member, experience, and size of the program to maximize sample variation. ${ }^{46}$ Age of the DL program was determined based on the year when the first DL project was started.

Selection criteria for interview candidates included: (1) extent of knowledge of the technology (for instance, did the individual have any information about the advantages and disadvantages of the technology and applicability of this particular technology in DLs?); (2) participation in the decision-making process to adopt or reject the technology (for example, did the individual have any influence on the decision-making process to adopt or reject the technology?); and (3) affiliation with academic libraries in institutions of higher education.

\begin{tabular}{|l|l|l|}
\hline \multicolumn{3}{|c|}{ TABLE 1 } \\
\hline Organizational Characteristics on Adoption of Innovations ${ }^{47}$ \\
\hline $\begin{array}{l}\text { Damanpour and } \\
\text { Schneider }\end{array}$ & $\begin{array}{l}\text { Criteria } \\
\text { Complexity, size, and external } \\
\text { communication (such as extra- } \\
\text { organizational professional activities) }\end{array}$ & Public organizations \\
\hline $\begin{array}{l}\text { Greenstein and } \\
\text { Thorin }\end{array}$ & $\begin{array}{l}\text { Age (DL program), orientation, } \\
\text { organization, and relationship with } \\
\text { surrounding academic departments } \\
\text { and information services }\end{array}$ & $\begin{array}{l}\text { DL programs of } \\
\text { the Digital Library } \\
\text { Federation (DLF) } \\
\text { member libraries }\end{array}$ \\
\hline Jaskyte & Age (organization) & Nonprofit organizations \\
\hline Rogers & Size & Any social structure \\
\hline
\end{tabular}




\section{Sampling}

Purposeful sampling, specifically maximum variation sampling, was employed when selecting key informants who had the best knowledge, expertise, and overview about the topic of the research. ${ }^{48}$ Patton sets no rules for the sample size in qualitative inquiry since "the validity, meaningfulness, and the insights generated from qualitative inquiry have more to do with the information richness of the cases selected and the observational/analytical capabilities of the researcher than with sample size." 49 Administrators' attitude toward innovation was an important factor of adoption of innovations; therefore, participation of DL administrators in the study was crucial to reflect this particular perspective. ${ }^{50}$

Purposeful sampling was used to select seven professionals from five DL programs in the United States. In terms of their responsibilities, three of them were in administrative positions (such as associate director), another three held technical positions with administrative responsibilities (such as digital projects manager), and one of them was a programmer. The participants varied in experience with DL-related projects, from eleven years to a year and a half, with an average experience of staff members of approximately seven years. Some of the respondents were responsible for initiating DL projects in their institutions. The staff size of the DL programs ranged from two to 77. In this sample, larger programs tended to be the older programs. Two of the programs could be categorized as large-sized programs, which were established in 1992 and 1997; another two could be classified as medium-sized programs, which were established in 1997 and 2002; and one of them could be considered small, initiated in 2003. Selected programs were also geographically distributed: one program was from the Western United States, one was from the Southeast, and three were from the Southwest.

The researcher stopped recruiting additional interviewees to meet the research goals when data saturation was reached. ${ }^{51}$ Data saturation is defined as the point in a data collection process where new information becomes redundant. ${ }^{52}$

\section{Data Analysis}

The interview data were analyzed using inductive analysis, which included processes of finding important themes and patterns in the data that could be used to explain the phenomenon. ${ }^{53}$ The codes were organized into a structure by separating them into major codes and sub-codes until themes (the codebook is available to interested readers by contacting the author) started to emerge from the data.

Documentary evidence was reviewed and incorporated to complement the interview data and provide additional insights and clarifications. A comprehensive member-check was conducted in order to have respondents evaluate the researcher's interpretation of findings and analyses of data from their perspectives. ${ }^{54}$ Respondents were in agreement with the findings. As appropriate, clarification was sought to enhance researcher's understanding of findings.

\section{Results and Discussion}

Findings suggest that characteristics of DL programs influence the decision-making process. The characteristics were categorized as organizational influences including organizational culture; a program's relationship with surrounding academic units and external entities; the management style and work structure; the focus and direction of a program; formalization (such as flexibility in hierarchal order); functional differentiation in a program; size and age of a program; administrative attitude toward change; financial resources; and program's expectations (such as user needs). These organizational influences are grouped into four categories: (1) organizational structure, (2) management style, (3) focus and direction, and (4) external relationships. 


\section{Organizational Structure}

Although DL programs studied are structured hierarchically as most traditional organizations are, the majority of respondents acknowledged that they incorporated a more flexible structure in practice by deemphasizing work rules and procedures, which, in turn, appeared to facilitate informal communication with internal and external colleagues, improve openness of staff to new ideas, and promote collaborative activities. One respondent described a loose structure as having the flexibility in employing temporary staff as needed and overlooking hierarchical distinctions among staff within the unit when sharing knowledge and providing input to ongoing projects. Flat structure was characterized as placement of staff with closely related job titles at the same level in the hierarchy. A representative comment included:

Within that [technology implementation] tier there is a database administrator, a network administrator... Below that tier [there] is a student technician tier...

It appears that these flexible structures exist alongside the hierarchical structures. One respondent from another large DL program explained this relationship with the following statement:

...reporting [to project management] is fairly traditional and hierarchical but in practice we are project-based and extensively matrixed. So, most people report on day-to-day basis to project management.

The small DL program in the study did not show an official organizational structure, as it would not be efficient use of resources for the institution because of the limited scope of the projects that were undertaken at the time. Midsize and large DL programs were divided into various functional units, and each of these units was responsible for different aspects of the program. Further, their responsibilities expanded from building digital collections to troubleshooting computer problems as DL programs grew. It appeared that DL programs adopted a project-driven approach, and these projects often involved people from different units of the DL programs, as well as from outside the DL programs. The structure of the relatively larger DL programs seemed similar to each other in terms of consisting of several groups or units with different responsibilities within their programs. Representative comments from respondents from midsize and large DL programs included:

... [the DL program] is organized into a variety of program areas. One, probably the largest, is technology...There are other large areas such as user services, publishing, building front-end [user interfaces], and preservation.

... we are not only responsible for just Web projects, but responsible for whether somebody's computer works or not. That is broad spectrum of responsibilities.

In terms of governance... there is a small cabinet [board] that reports to [the University Librarian] including myself, the head of user services, and head of licensed content.

A level of organizational complexity was present in DL programs in the form of "functional differentiation" in which units are placed under the umbrella of a larger group within the organization. A flexible approach to such organizational structure in DL programs resulted in a matrixed work structure that not only allowed DLs to 
draw people from different units of the program and external partners (see "External Relationships" for more information) together face to face or virtually to take part in different stages of a project but also promoted the adoption of innovations. ${ }^{55}$ Representative comments from small and midsize programs included:

All departments were very eager to get the digital library project live and we had the input from reference people... We had cataloging people involved.... the library systems department worked on infrastructure and design of the system.

My group is composed of three different units to help build collaboration within the IT [Information Technologies] units [including DL program as a unit] in the libraries... Trying to pull those three groups together has been interesting... We have to work together.

Additionally, another respondent from a large DL program discussed his/her involvement in DL projects as working together with faculty within the same institution and beyond: "[I] was involved in a lot of cross-faculty, school collaborations, and even inter-university collaborations." Documentary evidence from other DL programs corroborated this notion and collaboration among DL programs. For example, one DL program subcontracted another for work on a certain aspect of a project since the subcontracted DL program had the needed expertise.

There were also cases where some of these DL programs applied for external grants and worked on DL development projects as partners. A respondent from a large DL program acknowledged the need for facilitating communication among these units as well as partners involved in DL projects as their program grew in size and stated:

...this [setting up a project management unit] is next step in evolution of management in our library that helps facilitate the communication process as we grow.

Documentary evidence (such as a grant report) from a large DL program characterized the program as a matrixed organization that is divided into "functional divisions whose staff and capacities could be combined as appropriate to meet project and program needs." Furthermore, documentary evidence indicated that

...[the delivery of projects] requires aligned effort across a variety of functional units ([such as] ingest, programming, support services, web design and development, assessment). In this [matrixed] organizational model, communication is paramount.

The use of a matrixed organizational model was more intentional and often required in large projects in scope in larger DL programs. In the case of smaller DL programs, however, the model was employed out of necessity, as the skill set and knowledge base needed to take on any DL project required involvement of staff members from other units within and outside the library organization. Such level of organizational complexity appears to contribute positively in the adoption process, as it increases access to a diverse set of skills and knowledge base. ${ }^{56}$ Engagement in collaborative projects involving participants from different units, specifically in a matrixed work structure, created a social venue or platform that promoted informal communication. Such venues allowed for communication and information sharing between colleagues or coworkers, thus improving their skills and knowledge, and informing the decisionmaking process. ${ }^{57}$ 


\section{Management Style}

Management style of DL administrators emerged as an important factor contributing to adoption. More specifically, administrative attitude appeared to play an important role in the adoption process. Interview data indicated that, regardless of DL program administrators' background (that is to say, technical vs. nontechnical), DL administrators tended to rely on information and recommendations provided by their technical staff before making technology-related decisions. ${ }^{58}$ Further, data indicated that competence, reliability, ability, and openness to new ideas of their technical staff were major confidence-building factors for DL administrators and also were significant in promoting a climate where such decisions could be made collectively. ${ }^{59}$ Representative comments from DL administrators at different midsize and large programs included:

I depend heavily on their advice when I have to make [technology-related] decisions... Most of the time, I would take their advice.

...higher up the stack we definitely involve a larger number of people from a larger number of units. Lower down the stack, they tend to get made within the technology group primarily by its senior management.

Experience of one respondent in a technical position with administrative responsibilities in a midsize DL program was reflective of the significance of administrative attitude toward innovation under different administrators.

...[management style] changes with department head... Our new guy is more interested in following a best practices model. His management style is...very micromanager as opposed to the previous fellow who focused on more visionary and new generational perspectives.

These comments were indicative of a positive relationship between managerial attitude toward change and adoption of innovations at the organizational level. ${ }^{60}$ On the other hand, DL administrators appeared not to seek recommendations from technical staff regarding administrative decisions such as direction of the DL program, but did for technical decisions. A representative comment included:

...the direction of the program, where we are going, that is where, I think, I have more influence. I consider that as my chief role and responsibility....

Roles of administrators and technical staff in the decision-making process appeared to resemble the "dual-core model of organizational innovation," which suggested that organizations could be studied as if they were composed of two polar cores, administrative and technological cores, based on the area where an innovation occurred.$^{61} \mathrm{It}$ further suggested that skilled technical staff might have more weight in such decisions if administrative level staff lacked expertise in the area. ${ }^{62}$ However, DL administrators regardless of their background consulted with their staff and preferred to make technology-related decisions collectively.

In connection with a matrixed work structure and collective-innovation decision making at DL programs, the data suggested that DL programs incorporated a form of participative management style. ${ }^{63}$ Trust, specifically confidence of DL administrators in their staff, was an important component of participative management, since they assumed that technical staff had the knowledge, ability, or skills to contribute. ${ }^{64}$ However, the level of participation in management and decision-making processes was 
often limited to technical issues. Furthermore, respondents' degree of participation in decision-making processes varied from one DL program to another. Level of participation is defined as "the extent to which employees [formally and informally] influence final decisions." ${ }^{\prime 65}$ The program's size, structure, and attitude of administrative personnel were factors influencing the level of participation of technical staff in decision making.

DL programs were generally initiated as an effort to capitalize on advantages of the Internet and increase access by providing traditional library services online. These initiatives usually began as small-scale DL projects. DL programs became more functionally articulated to address different aspects of DL programs as they grew over time. Administrators' management styles played an important role in mediating the internal climate in terms of coordinating efforts, resolving conflicts, and paying attention to staff feedback as size (that is, number of staff) of the program and the number of projects undertaken increased.

Regardless of DL programs' size, management style in the DL program in part influenced information-seeking practice of technical staff and their contribution to decisionmaking processes since "empowerment and participation would make employees feel significant, committed to learning, team spirited and excited about their work." ${ }^{\prime 66}$ One respondent pointed out innovativeness and originality as important characteristics of his/ her information sources and acknowledged the speed of access to information as another important characteristic: "I need faster ways of getting information. Some information is out of date by the time it gets published in a print journal... We have got to find better ways to get very up-to-date information." Another respondent echoed a similar notion: "I am able to obtain first-hand and experience-based information from these message boards." Conferences and mailing lists were the most commonly used information sources and channels in addition to personal contacts. The following comments suggested how conference attendance was informally coordinated and executed at DL programs:

...we go to conferences....the staff here is fairly well connected to [a] variety of digital library programs and initiatives....through those networks there is tremendous amount of information acquisition and sharing.

...how that [information seeking about new developments in the field] worked was through a lot of conferences, training, national conferences I was actually flown to, and positive encouragement with regards to outreach....there was an encouragement towards personal learning experiences ... with regards to current technologies.

Conferences and other activities organized by professional associations also provided a venue for members to meet with their colleagues and build connections, which in turn benefited their DL programs. DL administrators not only encouraged staff to closely monitor trends in the field, attend specific conferences, and build informal connections with other DL programs, but also valued their feedback and input when making technology-related decisions. Focus and direction of the program were important influences in the use and selection of such information sources, since the staff was striving to accomplish the goals of the program mandated by its administrators or parent institution.

\section{Focus and Direction}

DL programs that had been initiated as small-scale projects in the 1990s have gradually grown into larger programs. In the context of this study, a program is described as a unit or department, which is often placed within the library and dedicated to the pro- 
duction, maintenance, delivery, and preservation of a wide range of digital resources. Although DL programs' main focus of digitizing analogue and print materials and providing access to those materials hasn't changed over the years, it has expanded to include preserving cultural heritage materials and providing support for scholarly publishing as the role of DLs changed and users' needs evolved. ${ }^{67}$ Representative comments from respondents at different DL programs included:

Another area would be publishing support services, supporting open scholarly communication and publishing and innovative projects... with regards to [delivering] audio and video [content online].

...we started to use an institutional repository application.

DL administrators made authority-innovation decisions regarding administrative issues including direction of the program and management style as discussed earlier. Direction of the DL program was closely associated with goals of the institution. DL programs' preference for applied over basic research was an important outcome of their focus. Participating DL programs primarily engaged in applied research where the results could be directly applied to their work and yielded more practical solutions compared to basic research. Respondents from two large DL programs discussed the orientation of their DL programs as handling more practical works and stated:

We would tend to think of ourselves undertaking mostly applied research...

We [DL program] are [a] production group. We are not research oriented. We don't have the luxury of being a research institution... We can't do that [research] anymore.

Another respondent from a midsize DL program acknowledged the intention of the DL program to engage in more research activities and mentioned:

We have always wanted to build ourselves as a research department [focusing on DL-related issues], but we have done more production and practical work.

Regardless of the focus and size of DL programs, respondents made validating statements that the DL programs were orientated toward carrying out more production work as opposed to research. Production work generally consisted of digitization and preservation activities. It also appeared that emerging areas, such as scholarly publishing, were considered production work. As addressed by one of the respondents: "[p]roduction [work] gets material out there and you have something [so] that others can start using." Another respondent from a different DL program acknowledged that his/her DL program benefited greatly from applied research and stated: "[w]hat we have learned in the research part of our work has [been] applied to [other] projects."

Respondents also talked about factors that prevented them from undertaking research. It appeared that increasing workload, deadline-oriented projects, growing demand for DL services, and budgetary constraints were important factors influencing the lack of research and development efforts. Respondents from relatively larger institutions discussed their current heavy workload as an important barrier. Representative comments included:

We have so many projects and demand to take care of and work for dissemination of those that. There is not much time for research. 
We don't typically undertake significant research for its own sake. Less research has paid off in terms of development of the program or development of new areas.

Another respondent from a midsize DL program drew attention to the lack of financial resources and indicated budgetary constraints as an important concern:

...we are much smaller in terms of the way we operate such a small level. Also, we don't have enough financial resources to fund an initiative that would cost a lot of money.

In relation to the "applied research" model, small and midsize DL programs were more intentional in looking up to other more established larger DL programs in the pursuit of "best practices" in the field. Representative comments included:

Even though I am working on a 'best practices model', I still would like to do things [with DL related technologies] that are more innovative."

...it is important [that] we are trying to meet all the national standards for best practices [in the DL field].

DL programs' preference for applied over basic research was an important aspect of their focus and direction. DL programs chose to engage primarily in applied research, the results of which could be directly applied to their work and yielded more usable solutions compared to basic research. DLs' orientation toward applied research was an important factor narrowing and directing the information-seeking practice of their members (see "External Relationships" for more information). Therefore, clarity of organizational goals and expectations were important drivers guiding staff members' information-seeking practices to grow professionally and gain competence. ${ }^{68}$

Staff activities involving knowledge creation, transfer, sharing, and other social interactions with colleagues in and outside the program were impacted by the focus on applied research. All respondents indicated that their use of online and offline communications were oriented toward attaining program goals, completing projects in hand, and meeting users' demands. Collegial interactions were regarded highly by respondents at large DL programs in accessing current information. A representative comment included:

[Staff and I have contacts at] California Digital Library [and] University of Michigan. There are colleagues and peers over there we talk to. We go to conferences and that kind of stuff. We might sit on advisory boards. [We are] more than casual observers. We pick up the phone and call individual people over there and talk to them about specific things.

Although collegial connections were important for staff at smaller DLs, the size of the DL program was an important influence for their reliance on vendor-specific mailing lists as a primary source in accessing new information about technological developments and solving problems. A representative comment included:

We usually seek [DL-related] information on vendor-specific discussion lists... If it is not a vendor[-]specific problem, we seek answers from other discussion boards through Digital Library Federation or the people that we met at conferences. I have learned a lot from the people I met at conferences. 
Focus and direction of the DL program influenced and shaped organizational culture, which impacted staff use and selection of technical information resources. The term "organizational culture," as used here, relates to individual members' perceptions of a shared belief system within the DL program; thus, providing a context for social interactions through norms and values in the form of guiding principles for its staff. ${ }^{69}$

Norms and values, constituting organizational culture, often reflected a position taken by senior management, which influenced actions and communications of staff members, including knowledge creation, transfer, and sharing..$^{70}$ The focus and direction of the DL program contributed to staff perceptions, which, in turn, influenced information-seeking practices of its members. In summary, the focus and direction of the DL program served as an important force guiding DL staff members' informationseeking practices, and shaping knowledge-sharing activities and DL program's goal and priorities.

\section{External Relationships}

External relationships refers to the DL programs' relationships with surrounding academic units and information services, such as an IT department, a library and information science (LIS) program, and with parties and actors that are outside their surrounding academic settings, including communities used to procure and share information. This was an important factor in understanding and characterizing respondents' interaction with others, including interdepartmental connections and those outside the organization in the context of CoPs.

All participating DL programs made validating statements of having good ties with surrounding academic departments and information services, including other library departments, IT department, LIS school, and faculty. DL programs benefited greatly from such connections not only by accessing their expertise and knowledge base, but also by acquiring their content and collections. One respondent said that his/her DL program was working closely with other library departments which owned collections (for example, music) and stated:

They [other library departments] are the ones with collections. We need to work with them and they need to let us do the digitization. The Government Documents [department] has tons of materials ... we have worked with them a lot.

One respondent pointed out his/her DL program's connections with other university system libraries as "long standing relationships" and described this as a complex relationship:

There is variety of committees and so forth, and [through] which [university] libraries staff can interact with the [DL program] staff. There are some programs in which there is great coordination of strategic development and partnering. There is an increasing degree of partnership with IT groups across the [university system].

Foundations for these connections were also established in campuswide or crosscampus committees. One respondent noted that members of his/her DL program participated in campuswide or cross-campus committees that enabled them "to obtain some insight rationalization and provide strategic direction for IT development and coordination." Another respondent from a different DL program explained that his/ her DL program's relationship with surrounding departments and information services included building connections to offer his/her program's services and facilitated work 
with them. He/she added: "...this is [the] first year where we have been talking to others to say we have services to offer."

These collaborative activities and connections, including access to other departments' or units' collections and expertise, appeared to be maintained through "library liaisons" or "project managers." Representative comments drawing attention to importance of such roles included:

Main contact with other departments about projects is by means of project managers. And of course, we have contacts with other departments through bibliographers, librarians.

...our connections with other departments [except the LIS Program] are maintained through library liaisons....we do work with other faculty on projects... [as] advisors and consultants.

Another respondent from a different DL program pointed out that his/her DL program benefited both financially and intellectually as his/her program interacted with the university's IT department and went on to indicate:

...We learn from them [IT department] as we work on some things together and as we ask for information or [their] advice.

Relationships between DL programs at institutions with library and information science schools (LIS) were reported to be much closer and stronger than those of other academic units. Members of DL programs often took part in teaching tasks at these schools and hired LIS students as interns, full-time, or part-time employees. One respondent discussed having geographical proximity to a library school as an important factor in fostering his/her DL program's relationship with LIS and stated: "[m]y boss ...is currently teaching a class at [LIS] and that is something that would probably be repeated. I personally initiated an internship program in which we would bring in [LIS] students for summer or semester oriented work that would help both parties." Another respondent from a different DL program continued: "[the] head of our digitization unit is adjunct faculty here at [LIS] and teaches a digitization class. And [the] manager of digitization also teaches occasionally in her area at [LIS] program."

In addition, the same respondent indicated that his/her DL program and LIS at the university were awarded a grant: "[w]e had a grant with the [LIS], which was a project... to develop a curriculum in digitization. We have a pretty strong tie with the [LIS]." Another respondent from a different DL program made concurring comments: "[r]ight now, we hire a lot of our [LIS] students and teach a lot of classes and do a lot of lectures [at LIS]. We have four of [LIS] graduates [employed] in the department."

Some of the participating academic libraries were members of various professional organizations and networks that have an influence on DL-related issues including use of DL technologies, digital preservation, and DL development activities. Participation in these organizations provided venues for DL programs to share their work and connect with other programs. These organizations included the Association of Research Libraries (ARL), Digital Library Federation (DLF), and Coalition for Networked Information (CNI). The DLF promotes work on DL structures, standards, preservation, and use; CNI is interested in various areas critical to present and future of DLs; and $\mathrm{ARL}$ is one of the sponsor organizations of CNI, and its member institutions are very active in the field. Further, these organizations engage in collaborative activities with each other in pursuit of their missions and goals. 
Respondents from different DL programs made validating statements that DL programs benefited from their participation in such organizations and encouraged their staff to participate. One respondent described his/her DL program's participation in both CNI and DLF as an active participant and stated:

...we try to represent the work [at DLF forums] that we are doing here, and we certainly gain considerably from our participation in that community [and] learning what other people are doing and attempting to take advantage of it. CNI is the same; we are an active contributor there.

Another respondent from a different DL program discussed his/her program's participation in CNI as oriented toward learning about latest trends and developments in the field.

In addition, one respondent talked about his/her DL program's participation in the open source community and stated:

We currently provide some of our software to the [DL] community through Sourceforge [sourceforge.net: a directory of in-development open-source software]...

The discussion of external relationships also indicated that the data provided evidence of entities (such as LIS, nonprofit organizations) that contributed to the formation of informal communities that can be characterized as CoPs. Further, collegial activities that were made possible through these relationships with other academic units and external entities appeared to play a central role in formation and continuation of these informal communities. In addition, such relationships in connection with focus and orientation of the DL program influenced the use of information resources and communication practices of respondents.

Relationships with surrounding academic units and external entities contributed to the CoP activities in which respondents were involved. These relationships were motivated by various objectives including knowledge sharing, learning from others, following the latest trends and developments in the field, content acquisition, or collaborative activities. The respondents' degree of participation in activities of CoPs appeared to be influenced and driven by the focus and orientation of the DL program. For example, one respondent indicated that his/her DL program's participation in such discussions varied as his/her topic of interest appears and mentioned:

I just take in the information and use it. In a lot of those [mailing list discussions], we are not that well-versed, so we cannot really offer a lot of opinions... For specific questions where if we know that we have answers, then we contribute.

The DL programs' focus on production work, engaging in applied research, and matrixed work structure influenced respondents' relationships with surrounding academic units and external entities especially in the context of members' information-seeking and communication practices. Respondents indicated that CoPs provided them with a rich and creative learning environment where they were able to gain considerably from diverse skills, ideas, and perspectives available in CoPs to meet organizational goals as discussed by Wenger. ${ }^{71}$ Data indicated that respondents knew where to go and whom to speak with when specific information was needed; otherwise, they ran into problems.

Participating in CoPs and following professional networks provided evidence for the existence of interpersonal relationships among their peers. Such interpersonal relation- 
ships were critical in CoP building. ${ }^{72}$ Respondents chose to participate in CoP activities not only because of their commitment and sense of belonging to the community but also because they appreciated the value of information gained and how it impacted their work activities. Moreover, fostering informal communication, engaging in collaborative activities, and knowledge sharing were essential to meet organizational goals. ${ }^{73}$

As discussed earlier, DL administrators sought external opinions and confirmation from trusted colleagues before or during the decision-making process. Respondents who were in nonadministrative positions generally engaged in nonmission critical decision making. Both administrators and technical respondents often chose to consult with trusted colleagues within and outside the boundaries of their programs and institutions because of perceived competence of such colleagues in terms of their skills, experiences, and background. Such social interactions can be characterized as CoPs. ${ }^{74}$ Furthermore, data suggested that closeness in terms of geographical proximity and openness of members of a program to others including other academic units facilitated formation of CoPs. Several academic units including LIS programs, the IT units, or other departments at the library were generally involved in DL projects directly as partners or indirectly providing support and guidance as needed. For example, LIS programs often provided the partnering DL program with expertise of their faculty, and students as interns or employees.

The data provided evidence of external parties (such as LIS or nonprofit organizations) that contributed to formation of informal communities that can be characterized as CoPs. Further, collegial activities that were made possible through these relationships with other academic units and external entities appeared to play a central role in formation and continuation of these informal communities. In addition, such relationships in connection with focus and orientation of the DL program influenced the use of information resources and the communication practices of respondents.

\section{Technology Adoption Decision Model}

The research has identified a variety of organizational-level influences that take place in DL technology adoption processes, including: (1) organizational structure, (2) management style, (3) focus and direction of the DL, and (4) external relationships. Regardless of size and age of the DL program, all programs incorporated a more flexible form of organizational structure that promoted an environment where contributions from interested parties were welcomed and technology-related decisions could be made collectively. Participation of other units and external partners in projects and decisionmaking processes were intentional for larger programs, whereas smaller programs had to collaborate out of necessity to complete the projects. A flexible approach to organizational structure appeared to promote more open and participatory management style, while one interviewee stressed personal characteristics of DL administrators as an important management characteristic. Information for technology decision flowed from bottom to upper ranks as administrators were receptive to recommendations from staff. However, the actual decision making and its implementation was a top-down process. Although the role of DL administrators in determining the program's focus and direction was evident, availability of resources as well as expanding responsibilities emerged as major determining factors for the focus of the program. In turn, staff members' information-seeking practices reflected such a resource-driven and solution-based approach, leading to best practices. These three interrelated inputs can be categorized as internal ones, as they were related to the program's internal dynamics.

The data showed that DL administrators and staff were often well connected with their peers and communities that spanned institutions. Such external parties served in different capacities for the staff and administrators. Relationships were established 
with contacts at other academic units on campus and outside through joint projects, professional organizations, and CoPs. Such relationships beyond the DL program boundaries served as connectors to up-to-date, original, validating information, which in turn influenced the decision-making process.

Attributes, such as program size, organizational culture, and availability of financial resources contributed to both internal and external influences. Program size was found to influence organizational structure and focus and direction, informing data-seeking practices of the staff. Though age of the program may be in part related to the program size, the age did not appear to have a moderating effect on internal and external inputs. Size of the program, however, was found to have a positive relationship with availability of financial resources. Larger programs had access to more financial resources, especially, through external funding sources because they were able to leverage their technical infrastructure, expertise, and partnerships with other programs to design and successfully secure and carry out large projects. Program administrators' attitudes toward change and beliefs appeared to have an influence on organizational culture and management style, which in turn informed staff's information seeking practices.

The research findings revealed the major influences that can be organized into internal inputs: (1) organizational structure, (2) management style, and (3) focus and direction; and external inputs: (4) external relationships. These are represented in the technology adoption decision model (see figure 1), which depicts the way major influences contribute to the decision-making process in DL environments.

\section{Implications and Further Research}

The findings of the current study have implications for both research and practice. For research, the findings were unique in increasing our understanding of the decisionmaking process as technologies rapidly evolve and are adopted in the DL environment. The tendency of DL programs to follow a best-practices approach because of expanding responsibilities and limited resources, regardless of their size and age, may serve as a threat to innovation in DLs. Further study measuring innovativeness of DL programs may help predict the future of DLs and their impact on the field.${ }^{75}$ Research, applying social network analysis, is also needed to quantitatively measure the relative importance of organizational influences on the decision-making process. An egocentric social network analysis of key DL staff members including administrators can help deepen our understanding of roles of CoPs as part of their personal information networks. ${ }^{76}$ On the other hand, a sociocentric network analysis focusing on members of a certain

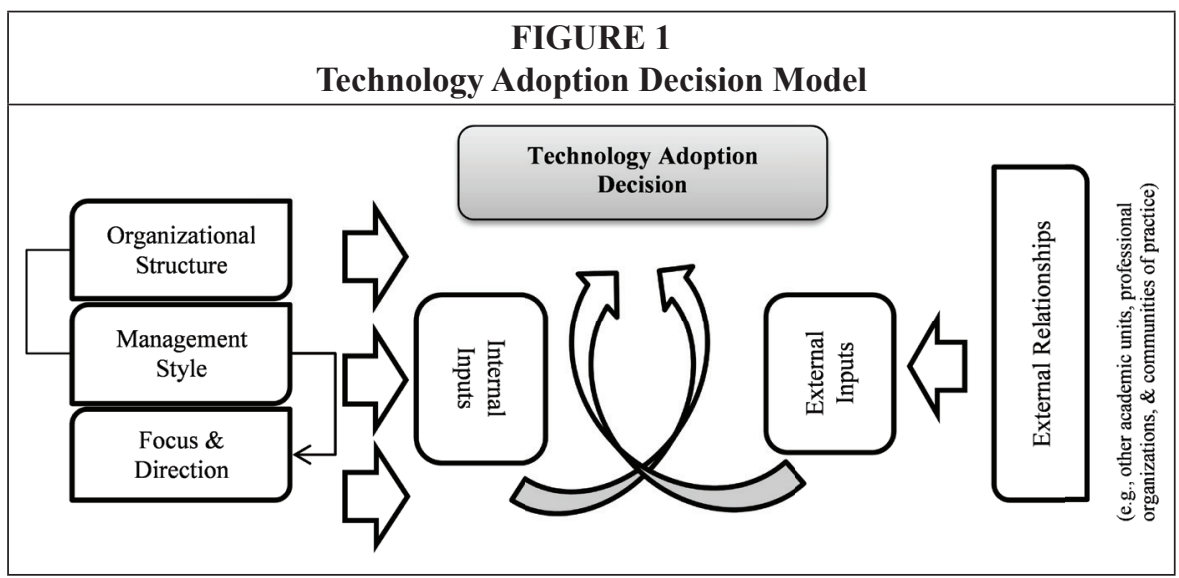


professional association (such as DLF) can help identify and map major actors and gatekeepers in DL-related information creation and dissemination that play a critical role in technology adoption decisions in DL environments. ${ }^{77}$ Examining differences in DL program resources, such as budgets and human capital, may help explain certain observations including information-seeking practices of staff, as well as focus and direction of the program.

For practice, there are implications for administrators as well as staff members. Administrators will be able to make more informed decisions with the knowledge of information flow in and outside the program, qualities of such information, and information sources. Identification of social and demographic characteristics of information sources that play critical roles in providing information, which in turn influence the decision-making process, can assist administrators not only to strategically use such information sources but also to better assess the value of information procured through them. Staff members can greatly benefit from resources embedded in DL CoPs in accessing up-to-date and experienced-based knowledge, and a collaborative problem-solving and learning environment. The sustainability of DLs can be enhanced by promoting an environment and culture of participatory decision making as DL programs grow in size and their responsibilities expand.

The decision-making process is a complex undertaking in which a number of influences such as organizational level ones are constantly at play. The technology adoption decision model illustrates the interrelationships among organizational influences, and the findings are rich in examples of the interdependent nature of internal and external inputs.

\section{Acknowledgements}

The author thanks William Moen for his guidance and support for this research, and Clara Chu for her review during preparation of this paper. The author would also thank the members of the DL programs who shared their insights and the anonymous reviewers for their constructive comments.

\section{Notes}

1. R. Reddy and I. Wladawsky-Berger, Digital Libraries: Universal Access to Human KnowledgeA Report to the President, 2001; Ronald Larsen and Howard Wactlar, Knowledge Lost in Information: Report of the NSF Workshop on Research Directions for Digital Libraries (Chatham, Mass.: University of Pittsburg, School of Information Sciences, June 15, 2003), available online at www.digitalpreservation.gov/news/2004/knowledge_lost_report200405.pdf [accessed 17 December 2014].

2. Michael Lesk, Understanding Digital Libraries, 2nd ed. (Boston: Elsevier, 2004).

3. C.L. Borgman, What Are Digital Libraries? Competing Visions, vol. 35, 1999; Reddy and Wladawsky-Berger, Digital Libraries: Universal Access to Human Knowledge.

4. Larsen and Wactlar, Knowledge Lost in Information.

5. Robert Akscyn and Ian Witten, "Report of First Summit on International Cooperation on Digital Libraries" (Workshop of ACM Digital Libraries ‘98, 1998), available online at http://web.archive.org/web/20010519140601/http://www.ks.com/idla-wp-oct98/ [accessed 11 June 2012]; Marcos André Gonçalves et al., "Streams, Structures, Spaces, Scenarios, Societies (5s): A Formal Model for Digital Libraries," ACM Trans. Inf. Syst. 22, no. 2 (Apr. 2004): 270-312, doi:10.1145/984321.984325; G. Marchionini, "Research and Development in Digital Libraries," in Encyclopedia of Library and Information Science, ed. Allen Kent, vol. 63 (New York: Marcel Dekker, 1998).

6. Marshall Breeding, "Introduction to Web Services," Library Technology Reports 42, no. 3 (June 5, 2006): 5.

7. Fatih Oguz, "An Exploration of the Diffusion of a New Technology from Communities of Practice Perspective: Web Services Technologies in Digital Libraries" (Ph.D. Diss., University of North Texas, 2007), available online at http://digital.library.unt.edu/ark:/67531/metadc3930/ [accessed 3 December 2012]; Kristina Jaskyte, "Predictors of Administrative and Technological Innovations in Nonprofit Organizations," Public Administration Review 71, no. 1 (2011): 77-86, doi:10.1111/j.1540-6210.2010.02308.x; Robert W. Zmud, “An Examination of 'Push-Pull' Theory 
Applied to Process Innovation in Knowledge Work," Management Science 30, no. 6 (June 1, 1984): 727-38, doi:10.1287/mnsc.30.6.727; R.L. Daft, "A Dual-Core Model of Organizational Innovation," Academy of Management Journal 21 (1978): 193.

8. Jaskyte, "Predictors of Administrative and Technological Innovations in Nonprofit Organizations."

9. Ibid.

10. Leonard W. D'Avolio et al., "From Prototype to Deployable System: Framing the Adoption of Digital Library Services," vol. 42, ed. Andrew Grove (2005), available online at http://eprints. rclis.org/6896/ [accessed 6 September 2013]; S. Al-Faresi and N. Patel, "The Design of an Adoption and Acceptance Framework for Mobile Digital Library Services," in 2012 International Conference on Information Society (i-Society) (2012), 216-24; Oguz, "An Exploration of the Diffusion of a New Technology"; Ronald C. Jantz, "A Framework for Studying Organizational Innovation in Research Libraries," College \& Research Libraries 73, no. 6 (Nov. 1, 2012): 525-41.

11. R.K. Yin, Case Study Research: Design and Methods (Thousand Oaks, Calif.: Sage Publications, 1994).

12. E.M. Rogers, Diffusion of Innovations, 5th ed. (New York: The Free Press, 2003).

13. Etienne Wenger, Richard McDermott, and William M. Snyder, A Guide to Managing Knowledge: Cultivating Communities of Practice (Boston: Harvard Business School Press, 2002).

14. Rogers, Diffusion of Innovations.

15. Ibid., 5.

16. Rogers, Diffusion of Innovations.

17. Daft, "A Dual-Core Model of Organizational Innovation"; Fariborz Damanpour, "Organizational Inertia and Momentum: A Dynamic Model of Strategic Change," Academy of Management Journal 34 (1991): 555-91; D. Leonard-Barton and I. Deschamps, "Managerial Influence in the Implementation of New Technology," Management Science 34 (1988): 1252; L.G. Tornatzky and K.J. Klein, "Innovation Characteristics and Innovation Adoption-Implementation: A MetaAnalysis of Findings," IEEE Transactions on Engineering Management 29, no. 1 (1982): 28-45; Aviv Shoham et al., "Testing an Organizational Innovativeness Integrative Model across Cultures," Journal of Engineering and Technology Management 29, no. 2 (Apr. 2012): 226-40, doi:10.1016/j.jengtecman.2012.01.002.

18. Daft, "A Dual-Core Model of Organizational Innovation"; Leonard-Barton and Deschamps, "Managerial Influence in the Implementation of New Technology"; Tornatzky and Klein, "Innovation Characteristics and Innovation Adoption-Implementation"; Rogers, Diffusion of Innovations; Zmud, "An Examination of 'Push-Pull' Theory"; Fariborz Damanpour and Marguerite Schneider, "Phases of the Adoption of Innovation in Organizations: Effects of Environment, Organization and Top Managers," British Journal of Management 17, no. 3 (2006): 215-36, doi:10.1111/j.14678551.2006.00498.x; Gary C. Moore and Izak Benbasat, "Development of an Instrument to Measure the Perceptions of Adopting an Information Technology Innovation," Information Systems Research 2, no. 3 (Sept. 1, 1991): 192-222, doi:10.1287/isre.2.3.192.

19. Daft, "A Dual-Core Model of Organizational Innovation"; Jaskyte, "Predictors of Administrative and Technological Innovations in Nonprofit Organizations."

20. Daft, "A Dual-Core Model of Organizational Innovation."

21. Zmud, "An Examination of 'Push-Pull' Theory."

22. Ibid.; Geoffrey A. Moore, Inside the Tornado: Marketing Strategies from Silicon Valley's Cutting Edge (New York: HarperCollins, 1995).

23. Fatih Oguz, Corrie V. Marsh, and Cliff Landis, "Collaboration through Communities of Practice in the Digital Age," in Technological Convergence and Social Networks in Information Management, vol. 96, ed. Serap Kurbanoğlu et al., Communications in Computer and Information Science (Springer Berlin Heidelberg, 2010), 18-30, available online at www.springerlink.com/content/ u88164g556068230/abstract/ [accessed 29 July 2012].

24. Jaskyte, "Predictors of Administrative and Technological Innovations in Nonprofit Organizations."

25. Robert D. Stueart and Barbara B. Moran, Library and Information Center Management (Westport, CT: Libraries Unlimited, 2007).

26. M.P. Marchant, "Participative Management, Job Satisfaction, and Service," Library Journal 107 (1982): 782-84; G.J. Oosthuizen and A.S.A. Du Toit, "Participative Management in Academic Library Services," Library Management 20 (1999): 213-19.

27. Daryl R. Conner, Managing at the Speed of Change: How Resilient Managers Succeed and Prosper Where Others Fail (New York: Random House Digital, Inc., 1993).

28. Stueart and Moran, Library and Information Center Management.

29. Rogers, Diffusion of Innovations.

30. Kraut, Robert E., Robert S. Fish, Robert W. Root, and Barbara L. Chalfonte. “Informal Communication in Organizations: Form, Function, and Technology." In Human Reactions to Technology: 
The Claremont Symposium on Applied Social Psychology, edited by I. S. Oskamp and S. Spacapan. Beverly Hills: Sage Publications, 1990.; Carol M. Lehman and Debbie D. DuFrene, Business Communication, 15th Edition (Mason, OH: Thomson/South-Western, 2007).

31. Kraut et al., "Informal Communication in Organizations: Form, Function, and Technology."

32. Lehman and DuFrene, Business Communication, 15th Edition.

33. A. Persaud, U. Kumar, and V. Kumar, "Harnessing Scientific and Technological Knowledge for the Rapid Deployment of Global Innovations," Engineering Management Journal 13, no. 1 (2001): 12; Kraut et al., "Informal Communication in Organizations: Form, Function, and Technology."

34. R. Cross et al., "Knowing What We Know: Supporting Knowledge Creation and Sharing in Social Networks," Organizational Dynamics 30, no. 2 (2001): 100-20; Damanpour and Schneider, "Phases of the Adoption of Innovation in Organizations."

35. Edgar H. Schein, Organizational Culture and Leadership (San Fransisco, CA: John Wiley \& Sons, 2004).

36. Jaskyte, "Predictors of Administrative and Technological Innovations in Nonprofit Organizations"; E.L. Lesser and J. Storck, "Communities of Practice and Organizational Performance," IBM Systems Journal 40 (2001): 831-931; ThuyUyen H. Nguyen, "Information Technology Adoption in SMEs: An Integrated Framework," International Journal of Entrepreneurial Behaviour \& Research 15, no. 2 (Mar. 6, 2009): 162-86, doi:10.1108/13552550910944566; Rogers, Diffusion of Innovations.

37. Wenger, McDermott, and Snyder, A Guide to Managing Knowledge.

38. S.P. Borgatti, "Communities of Practice" (2004), available online at www.analytictech.com/ mb119/communities_of_practice.htm [accessed 19 April 2013].

39. Wenger, McDermott, and Snyder, A Guide to Managing Knowledge.

40. Ibid.

41. Wenger, McDermott, and Snyder, A Guide to Managing Knowledge.

42. Rogers, Diffusion of Innovations.

43. Levitt, J. "From EDI to XML and UDDI: A Brief History of Web Services." Information Week, October 1, 2001, available online at http://www.informationweek.com/story/IWK20010928S0006 [accessed 20 May 2012]

44. M.Q. Patton, Qualitative Research and Evaluation Methods (Thousand Oaks, Calif.: Sage Publications, Inc., 2002); Yin, Case Study Research: Design and Methods.

45. Yin, Case Study Research: Design and Methods.

46. The Digital Library: A Biography Digital Library Federation (Council on Library and Information Resources, 2002); Damanpour and Schneider, "Phases of the Adoption of Innovation in Organizations"; Kristina Jaskyte, "Does Size Really Matter? Organizational Size and Innovations in Nonprofit Organizations," Nonprofit Management and Leadership 24, no. 2 (2013): 229-47, doi:10.1002/nml.21087; Rogers, Diffusion of Innovations.

47. Damanpour and Schneider, "Phases of the Adoption of Innovation in Organizations"; D. Greenstein and S.E. Thorin, The Digital Library: A Biography Digital Library Federation (Washington, D.C. : Council on Library and Information Resources, 2002); Jaskyte, "Does Size Really Matter?"; Rogers, Diffusion of Innovations.

48. Patton, Qualitative Research and Evaluation Methods; C.M. Varkevisser, I. Pathmanathan, and A. Brownlee, Designing and Conducting Health Systems Research Projects (Amsterdam, The Netherlands: KIT Publishers, 2003).

49. Patton, Qualitative Research and Evaluation Methods.

50. Damanpour and Schneider, "Phases of the Adoption of Innovation in Organizations."

51. M.C. Hoepfl, "Choosing Qualitative Research: A Primer for Technology Education Researchers," Journal of Technology Education 9, no. 1 (1997).

52. R.C. Bogdan and S.R. Biklen, Qualitative Research for Education: An Introduction to Theory and Methods (Boston: Allyn and Bacon, 1992).

53. J.P. Gall, M.D. Gall, and W.R. Borg, Applying Educational Research: A Practical Guide (New York: Addison Wesley Longman, Inc., 1999); E.W. Eisner, The Enlightened Eye: Qualitative Inquiry and the Enhancement of Educational Practice (New York: Macmillan, 1991).

54. Y.S. Lincoln and E.G. Guba, Naturalistic Inquiry (Beverly Hills: Sage Publications, Inc, 1985);

Patton, Qualitative Research and Evaluation Methods.

55. Damanpour, "Organizational Inertia and Momentum."

56. Damanpour and Schneider, "Phases of the Adoption of Innovation in Organizations."

57. D. Cohen and L. Prusak, In Good Company: How Social Capital Makes Organizations Work

(Boston: Harvard Business School Press, 2001).

58. Damanpour and Schneider, "Phases of the Adoption of Innovation in Organizations."

59. Lesser and Storck, "Communities of Practice and Organizational Performance"; J. Nahapiet and S. Ghoshal, "Social Capital, Intellectual Capital, and the Organizational Advantage," The Academy of Management Review 23 (1998): 242-66.

60. Damanpour, "Organizational Inertia and Momentum"; Damanpour and Schneider, "Phases 
of the Adoption of Innovation in Organizations"; Nguyen, "Information Technology Adoption in SMEs"; Leonard-Barton and Deschamps, "Managerial Influence in the Implementation of New Technology"; Zmud, "An Examination of 'Push-Pull' Theory Applied to Process Innovation in Knowledge Work."

61. Daft, "A Dual-Core Model of Organizational Innovation."

62. Ibid.

63. Marchant, "Participative Management, Job Satisfaction, and Service"; Oosthuizen and Du Toit, "Participative Management in Academic Library Services."

64. Marchant, "Participative Management, Job Satisfaction, and Service."

65. Oosthuizen and Du Toit, "Participative Management in Academic Library Services."

66. Ibid.

67. Greenstein and Thorin, The Digital Library.

68. Elizabeth Wolfe Morrison, "Information Seeking within Organizations," Human Communication Research 28, no. 2 (Apr. 1, 2002): 229-42, doi:10.1111/j.1468-2958.2002.tb00805.x.

69. N.H. Abdullah and A. Othman, "The Influence of Leadership on Organizational Culture and Its Effects on Knowledge Management Initiative," in Proceedings of the International Conference on Knowledge Management (ICKM), 2005.

70. J. Liedtka, “Organizational Value Contention and Managerial Mindsets," Journal of Business Ethics 10 (1991): 543-57; K.B. Detienne et al., "Toward a Model of Effective Knowledge Management and Directions for Future Research: Culture, Leadership, and Ckos," Journal of Leadership $\mathcal{E}$ Organizational Studies 10 (2004): 26-29; E. Beerkens, "Global Opportunities and Institutional Embeddedness; Higher Education Consortia in Europe and Southeast Asia," in CHER Conference (CHEPS, 2004), available online at www.beerkens.info/files/Beerkens\%20CHER\%20Conference. pdf [accessed 20 May 2012].

71. Wenger, Etienne. "Supporting Communities of Practice: A Survey of Community-Oriented Technologies." The Council of CIOs of the US Federal Government, January 29, 2010, available online at https://guard.canberra.edu.au/opus/copyright_register/repository/53/153/01_03_CP_ technology_survey_v3.pdf [accessed 22 March 2016].

72. Cross et al., "Knowing What We Know."

73. Cohen and Prusak, In Good Company.

74. Wenger, Supporting Communities of Practice.

75. Shoham et al., "Testing an Organizational Innovativeness Integrative Model across Cultures."

76. Caroline Haythornthwaite, "Social Network Analysis: An Approach and Technique for the Study of Information Exchange," Library E Information Science Research 18, no. 4 (1996): 323-42, doi:10.1016/S0740-8188(96)90003-1.

77. Ibid. 